\title{
Vitamin D Deficiency in E.N.T. Patients
}

\author{
M. K. Taneja $\cdot$ Vivek Taneja
}

Received: 16 November 2012/ Accepted: 23 November 2012/Published online: 1 December 2012

(C) Association of Otolaryngologists of India 2012

\begin{abstract}
A prospective study to observe the prevalence of deficiency of vitamin $\mathrm{D}$ in out patients of otolaryngology clinic at Indian Institute of ear diseases, Muzaffarnagar. The patients attending outpatient of otolaryngology clinic with various complaints and not responding to conventional treatment were advised for assessment of vitamin $\mathrm{D}$ [25 (OH)D] level in blood. The age, sex, occupation, colour of skin, chief complaints, obesity, provisional diagnosis, and incidence of sun exposure was noted in all cases. A total of 86 patients were examined, maximum patients were in the age group of 7-15 years. The chief complaints in majority of the patients were sore throat with recurrent upper respiratory tract infection. Only in three patient's vitamin D level was found to be with in normal limits. In rest $83(96.51 \%)$ it was either deficient $57(66.28 \%)$ or insufficient $21(24.42 \%)$. The incidence of vitamin D deficiency is extremely common in Ear Nose Throat disease (E.N.T.) patients. The results of vitamin supplementation were promising in cases of benign paroxysmal positional vertigo with cervical spondylosis and URTI with asthma, empirical supplementation of vitamin D in all E.N.T. patients not responding to conventional treatment is worth trying. At place of sun screen, use of pomegranates and blueberries may be encouraged to prevent sunburn and eliminate Vitamin D deficiency.
\end{abstract}

M. K. Taneja ( $\square)$

Chief Indian Instiute of Ear Diseases, Meerut, India

e-mail: ijo_editor@rediffmail.com

V. Taneja

Resident Subharti Medical College, Meerut, India
Keywords Vitamin D deficiency · URTI .

Bronchial asthma · B.P.P.V. · Cervical spondyliosis . E.N.T

\section{Introduction}

The role of vitamin D in prevention of respiratory tract infection, cochlear deafness or demineralization of bone is gathering evidence hence this study was conducted to evaluate the incidence of Vitamin D deficiency in out door patients of otoryngology clinic with various symptoms and signs of E.N.T and related diseases.

Neils Finsen was awarded nobel Prize for using high intensity light by arc lamp in skin tuberculosis. Since then various researches are going on to treat and cure infection by sun rays. The upper respiratory tract mucosa is the initial site of contamination and infection hence nature has provided several protective mechanisms out of which is the ciliary movement of the respiratory mucosa and its mucous a gel like structure which removes the inhaled invading microbes. On invasion to body microbes are taken care by the locally available antimicrobial peptides.

There are about 200 viruses apart from pneumococci, meningocci, and streptococci, which can cause common cold and acute otitis media. Most of these pathogens are sensitive to anti-microbials, cathelicidin and defensin released by the body defense mechanism under the influence of vitamin D [1-4]. The Upper respiratory tract infection (URTI) results in acute neutrophilic infiltration in respiratory epithelium and production of mucous. With increased amount of mucous, patient is more prone to infections and decrease in pancreatic secretion, which may result in mal-absorption of fat, consequently decreased absorption of vitamin D [5]. 
The prophylactic role of vitamin $\mathrm{C}$ has been embarked and been used for decades in the prevention of recurrent URTI. The ergocalciferol and cholecalciferol are less commonly used as vitamin supplement and rarely used as immunomodulator. Though some foods also contain these pro-vitamins, due to inadequate sunlight exposure or dark skin, active vitamin D (25 hydroxy vitamin D and 25 $(\mathrm{OH}) \mathrm{D})$ level varies in the body, which may result in reduced innate immunity. Winter time vitamin D insufficiency may explain seasonal variation and more frequent URTI. Apart form darker pigmentation, use of sun screens, wearing of clothing, clouds, environmental pollution limits the penetration of ultraviolet light B. Aging is also associated with decrease concentration of 7 dehydro cholesterol in skin; a common reason may be attributed for vitamin D insufficiency and old age deafness.

Vitamin D deficiency is now associated with increased risk of certain cancer, autoimmune and infectious diseases [6]. Vitamin D regulates more than 200 genes including genes for cellular proliferation and apoptosis [5]. Vitamin D regulated gene expression through binding with Vitamin D Receptor (VDR), which modulates the expression of genes.

Pathogenic antigens interact with toll-like receptors on macrophages to up regulate the expression of gene that codes for the vitamin $\mathrm{D}$ receptor and for the $\mathrm{I}^{\alpha}$ hydroxylase enzyme that convert $25(\mathrm{OH}) \mathrm{D}$ [7-9] to the biologically active 1, 25 dihydroxy vitamin $\mathrm{D}$ and it enhances the production of cathelicidin hCAP-18 (LL-37) [10], which enhances microbial killing in phagocytic vacuoles, acts as a chemotractant for neutrophils and monocytes [11, 12]. Vitamin D is very important for muscle function and it reduces the risk of falls in old persons. If a person is suffering from insomnia or depression the cause may be vitamin D deficiency.

The respiratory epithelium can also convert inactive vitamin $\mathrm{D}$ to active 1, 25 (OH)D 3 to increase the expression of vitamin $\mathrm{D}$ regulated genes, which provide definite innate immunity at the site [13]. Thus, vitamin D is a key, immunomodulator and its deficiency will increase the incidence of URTI leading to otitis media retraction pocket and cholesteatoma, again deficiency of vitamin D will lead to low bone density and osteoporosis, hence osteoclastic activity of cholesteatoma will be enhanced [14].

An inverse association between maternal intake of vitamin D during pregnancy and incidence of infection, low birth weight, premature birth has been reported [15, 16]. Hence low serum vitamin D levels in the pregnant women must be considered, which may finally lead to in severe congenital hearing loss in baby.

The role of vitamin $\mathrm{D}$ deficiency has been attributed to cochlear deafness, Meniere's disease and otosclerosis including cochlear otosclerosis representing with trough shaped pure tone audiogram with a dip during 1 and $2 \mathrm{kHz}$ frequencies [17].

The calcium and phosphorus content of the woven bone of the otic capsule are much higher than other bones hence may be more affected by deficient vitamin D levels.

Again demineralization of otic capsule, may lead to degenerative changes in the spiral ligament, stria vascularis and cochlear hair cells [18]. A significant reduction in the brainstem amplitude has been observed in vitamin D depleted diet in albino rats by Brooks and Morrison [19].

\section{Materials and Methods}

The patients attending outpatient of otolaryngology clinic with various complaints and not responding to conventional treatment were advised for assessment of vitamin D [25 (OH)D] level in blood. The age, sex, occupation, colour of skin, chief complaints, obesity, provisional diagnosis, and incidence of sun exposure was noted in all cases. A quick general history and examination was also under taken for presence of other medical conditions.

\section{Results}

A total of 86 patients in the period from 1st May to 30th September 2012 were examined. Maximum patients were in the age group of 7-15 years 40 were male 46 female as show in Table 1. Only in three patients vitamin D level was in normal limits. In rest $83(96.51 \%)$ it was below $25 \mathrm{nmoL} / \mathrm{mL} 10(11.63 \%)$ below $25-50 \mathrm{nmoL} / \mathrm{mL}$ in 57 $(66.28 \%)$ and $50-75 \mathrm{nmoL} / \mathrm{mL} 16(18.61 \%)$ cases.as shown in Table 2.

The chief complaints in majority of the patients were sore throat with recurrent upper respiratory tract infection, details of complaints are shown in Table 3.

Table 1 Age and sex distribution

\begin{tabular}{lcccc}
\hline Age group & No. of patients & $\%$ & \multicolumn{2}{l}{ Sex } \\
\cline { 4 - 5 } & & & Male & Female \\
\hline 1-7 year & 18 & 20.93 & 10 & 8 \\
7-15 years & 25 & 29.07 & 14 & 11 \\
15-25 years & 17 & 19.77 & 7 & 10 \\
25-40 years & 19 & 22.09 & 8 & 11 \\
40-60 years & 5 & 5.81 & 1 & 4 \\
60 years-onwards & 2 & 2.33 & 0 & 2 \\
Total & 86 & 100 & 40 & 46 \\
\hline
\end{tabular}


Table 2 Serum vitamin D level

\begin{tabular}{lrl}
\hline Serum vitamin D levels & No & $\%$ \\
\hline$<10 \mathrm{nmoL} / \mathrm{mL}$ & 5 & 5.81 \\
$10-25$ & 5 & 5.81 \\
$25-50$ & 57 & 66.28 \\
$50-75$ & 16 & 18.61 \\
$>75$ & 3 & 3.49 \\
$>400$ & 0 & 0.00 \\
Total & 86 & 100 \\
\hline
\end{tabular}

Table 3 Presenting complaints

\begin{tabular}{lcc}
\hline Chief complaints & No. & \% \\
\hline Sore throat & 18 & 20.93 \\
Sore throat with URTI & 21 & 24.42 \\
Tinnitus sinusitis & 12 & 13.95 \\
Recurrent URTI with bronchial asthma & 5 & 5.81 \\
Atelectic ear following cholesteatoma surgery & 1 & 1.16 \\
Recurrent ear discharge with central perforation & 7 & 8.15 \\
Recurrent ear discharge with cholesteatoma & 4 & 4.65 \\
Sensorineural deafness & 5 & 5.81 \\
Sensorineural deafness with tinnitus & 5 & 5.81 \\
Vertigo with tinnitus & 2 & 2.33 \\
Vertigo with sensori deafness & 2 & 2.33 \\
Vertigo with cervical spondyliosis & 3 & 3.49 \\
Cheilosis & 1 & 1.16 \\
Total & 86 & 100 \\
\hline
\end{tabular}

Table 4 Skin color type and Vitamin D levels

\begin{tabular}{lrllll}
\hline Colour of skin & No. & $\%$ & \multicolumn{2}{l}{ Vitamin D level } \\
\cline { 4 - 6 } & & & Avg & Min & Max \\
\hline Very fair & 0 & 0 & 0 & 0 & 0 \\
Fair & 39 & 45.35 & 44.50 & 7.0 & 139.0 \\
Wheatish & 20 & 23.26 & 41.80 & 11.8 & 64.4 \\
Brownish & 19 & 22.09 & 45.56 & 5.8 & 116 \\
Dark brown & 8 & 9.30 & 32.15 & 16.67 & 49.2 \\
Dark & 0 & 0 & 0 & 0 & 0 \\
Total & 86 & 100 & 31.73 & 5.8 & 139.0 \\
\hline
\end{tabular}

The color of skin type and vitamin D level was matched as of fitz patriek skin type divided in six categories result shown in Table 4.

The incidence of dental caries was quite high in our group and it was closely associated in cases of cholesteatoma hence the cases of recurrent URTI with dental caries should be investigated for vitamin D and serum calcium level to prevent complication in terms of cholesteatoma.
None of the patient gave a specific history of deliberate sun exposure/sun bath for health reason.

\section{Discussion}

In our study, $96.51 \%$ were deficient for vitamin D. Baitlay et al. in E N T patients have reported that $2 \%$ had the level $17.5 \mathrm{nmol} / \mathrm{L}$ or less, $58 \%$ below $50 \mathrm{nmol} / \mathrm{L}$ and all were below $80 \mathrm{nmol} / \mathrm{L}$ [20] while in our study there were 3 patients having more than $80 \mathrm{nmol} / \mathrm{L}$ vitamin $\mathrm{D}$ level, Rockell et al. has reported only $84 \%$ below $80 \mathrm{nmol} / \mathrm{L}$ out of which $48 \%$ below $50 \mathrm{nmol} / \mathrm{L}$ and $3 \%$ below $17.5 \mathrm{nmoL} / \mathrm{L}$ [21]. Ginde et al. [7] reported $2 \%$ population below $10 \mathrm{ng} / \mathrm{ml}$ and $10 \%$ below $30 \mathrm{ng} / \mathrm{ml}$ and the incidence of URTI was $19 \%$ while it was $24.42 \%$ in our series.

In our study we could see that significantly lower levels were seen in upper socio economic group while Linday et al. has also derived that no difference in status of vitamin D level as gender, race, economic status or vitamin use was considered. Bantley et al. [22] has also observed deficiency in all ranges \& similar proportion. In our study we can not find out a case of rickets even though it was common once upon a time in India. The association of diabetes with ENT disorder was observed in 9 cases all of them were given weekly sachet of Vitamin D 60,000 units along with all other supportive treatment and reduction in weight the results were promising but it warrants specific long term study to conclude in favour of vitamin D.

There was a case of full term pregnant woman attending E.N.T out patient department for chronic distressing cough not responding to all conventional treatment. Her vitamin D level was quite low $(5.8 \mathrm{nmol} / \mathrm{L})$ along with low serum calcium level. Patient was developing sign \& symptom of preeclampsia. High doses of calcium supplementation are attributed to prevent preeclampsia hence we propose screening for vitamin $\mathrm{D}$ level in all pregnant women and suitably supplemented to decrease the incidence of eclampsia.

Low serum levels of vitamin D metabolites may lead to osteoclastic activity (Osteoporosis) that is mobilization of calcium from bones may also result in secondary hyper parathyroidism. Radiologically it can not be detected until more than $35 \%$ demineralization of bone has been done. Demineralization of cochlea has also been observed in temporal bone tomography. We can hypothesize that osteoclastic activity will be potentially aggravated in deficiency of vitamin D. Now it is well known that deficiency of vitamin D lowers the immunity and may precipitate the recurrent attacks of upper respiratory tract infection leading to Eustachian tube dysfunction which may complicate as cholesteatoma. We have to work out the deficiency of vitamin D and blood level of calcium to prevent this drastic disorder (Cholesteatoma). 
Replacement of vitamin D and calcium should be done carefully as higher calcium level may lead to extra skeletal calcification but significantly high doses has to be given for months together. Toxicity above $400 \mathrm{nmoL} / \mathrm{mL}$ has been considered worth alarming. High doses of vitamin A procured from cod-liver oil can be considered as a counter active substitution. The ability of vitamin $\mathrm{D}$ to decrease the risk of distal colorectal adenoma in woman can be attenuated by high intakes of preformed vitamin A.

Apart from inadequate sunlight exposure and dietary intake, impaired intestinal absorption, poor liver function or disease, chronic renal disease and anticonvulsant drug may also lead to lower vitamin D levels. The incidence is more in asians, may be due to poor absorption of ultra violet rays due to melanin and/or dietary or genetic factors. Ultraviolet (UV) B radiation with wave length of 290-320 nano meters converts cutaneous dehydrocholesterol to previtamin $\mathrm{D}_{3}$. The bright scorchy sunlight may itself destroy the vitamin D produced in the skin. It has been observed that vitamin $\mathrm{D}$ produced in limbs may be more readily available than from the abdomen. Its suits our culture hence even limited body exposure is sufficient average $15 \mathrm{~min}$ sun exposure to face and both limbs on alternate days between 10:00 A.M. to 3:00 P.M. is sufficient.

\section{Conclusion}

The incidence of vitamin D deficiency is extremely common in E.N.T patients. The result of vitamin D supplementation is promising in cases of benign paroxysmal positional vertigo with cervical spondylosis and URTI with asthma, since the assay of vitamin D level is costly hence repeated checkup is not cost effective.

Empirical supplementation of vitamin D in all E.N.T patients is worth trying if patient is not willing for assessment of vitamin D specifically in patients of recurrent attack of acute otitis media or adenotonsillis.

We can not substitute the benefit of sun exposure but certainly to enhance immunity we can supplement vitamin D. At place of sun screen, use of pomegranates and blueberries may be encouraged to prevent sunburn and tanning to prevent deficiency of vitamin D, 200 IUs up to 50 years, 400 IUs up to 60 years and 600 IUs above it may go up to 2,000 IUs in winters supplementation is advised.

\section{References}

1. Muhe L, Lulseged S, Mason KE, Simoes EA (1997) Case-control study of the role of nutritional rickets in the risk of developing pneumonia in Ethiopian children. Lancet 349:1801-1804

2. Bikle D (2009) Nonclassic actions of vitamin D. J Clin Endocrinol Metab 94:26-34
3. Yim S, Dhawan P, Ragunath C, Christakos S, Diamond G (2007) Induction of cathelicidin in normal and $\mathrm{CF}$ bronchial epithelial cells by 1, 25-D3. J Cyst Fibros 6:403-410

4. Wayse W, Yousafzai A, Mogale K, Filteau S (2004) Association of subclinical dihydroxivitamin vitamin D deficiency with severe acute lower respiratory tract infections in Indian children under 5 years. Eur J Clin Nutr 58:563-567

5. Hughes DA, Norton R (2009) Vitamin D and respiratory health. Clin Exp Immunol 158:20-25

6. Holick MF, Chen TC (2008) Vitamin D deficiency: a worldwide problem with health consequences. Am J Clin Nutr 87:1080S$1086 \mathrm{~S}$

7. Ginde AA, Mansbach JM, Camargo CA Jr (2009) Association between serum 25-hydroxy vitamin D level and upper respiratory tract infection in the third national health and nutrition examination survey. Arch Intern Med 169:384-390

8. Reichel H, Koeffler HP, Bishop JE, Norman AW (1987) 25-Hydroxyvitamin D3 metabolism by lipopolysaccharide-stimulated normal human macrophages. J Clin Endocrinol Metab 64:1-9

9. Liu PT, Stenger S, Li H, Wenzel L, Tan BH, Krutzik SR (2006) Toll-like receptor triggering of a vitamin D-mediated human antimicrobial response. Science 311:1770-1773

10. Webber G, Heilborn JD, Chamorro Jimenez Cl, Hammarsjo A, Torma H, Stahle M (2005) Vitamin D induces the antimicrobial protein hCAP18 in human skin. J Invest Dermatal 124: $1080-1082$

11. Gombart AF, Borregaard N, Koeffler HP (2005) Human cathelicidin antimicrobial peptide (CAMP) is a direct target of the vitamin $\mathrm{D}$ receptor and is strongly up-regulated in myeloid cells by 1,25-dihydroxy vitamin D3. FASEB J 19(9):1067-1077

12. Liu PT, Stenger S, Tang DH, Modlin RL (2007) Cutting edge: vitamin D-mediated human antimicrobial activity against $\mathrm{Myco}$ bacterium tuberculosis is dependent on the induction of cathelicidin. J Immunol 179:2060-2063

13. Hansdottir S, Monick MM, Hinde SL, Lavan N, Look DC, Hunninghake GW (2008) Respiratory epithelial cells convert inactive vitamin $\mathrm{D}$ to its active form: potential effects on host defense. J Immunol 181:7090-7099

14. Taneja MK, Vivek Taneja (2012) Role of vitamin D in prevention of deafness. Indian J otology 18(2):55-57

15. Cammargo CA, Rifas-Shiman SL, Liuonjua AA, Burris HH, Kleinman K, Huh SY (2006) Prospective study of maternal intake of vitamin $\mathrm{D}$ during pregnancy and risk of wheezing illeness in children at age 2 years. J Allergy Clin Immunol 117:721-722

16. Devereux G, Litonjua AA, Turner SW, Craig LC, McNeill G, Martindale S (2007) Maternal vitamin D intake during pregnancy and early childhood wheezing. Am J Clin Nutr 85:853-859

17. Brookes GB (1985) Vitamin D deficiency and deafness: 1984 update. Am J Otology 6(1):102-107

18. Taneja MK (2012) Role of ENT surgeons in the national program for prevention and control of deafness. Indian J otology 3(18): $119-121$

19. Brookes GB, Morrrison AW (1981) Vitamin D deficiency and deafness. Br Med J Clin Res Ed 283:273-274

20. Bartley Jim, Reid David, Morton Randall P (2009) Prevalence of vitamin $\mathrm{D}$ deficiency among patients attending a general otolaryngology clinic in south auckland. Annals Otology Rhinology Laryngol 118(5):326-328

21. Rockell JEP, Skeaff CM, Williams SM, Green TJ (2006) Serum 25 hydroxyvitamin D concentrations of New Zealanders aged 15 and older. Osteoporos Int 17:1382-1389

22. Linday LA, Shindledecker RD, Dolitsky JN, Chen TC, Holick MF (2008) Plasma 25-Hydroxy vitamin D levels in young children undergoing placement of tympanostomy tubes. Annals Otology Rhinology Laryngol 117(10):740-744 